that the hospitals which have developed the diagnostic phase of medicine so extensively may develop also the therapeutic phase, but it seems that the tendency is not that way. Outside of special therapeutic procedures, such as operations, etc., treatment will be largely in the hands of the general practitioner. Successful treatment in the case of many diseases must be applied over a considerable period of time. It is only the general practitioner with his continuous surveys, who can record the actual results and make proper deductions therefrom. It seems to me that in the line of treatment there are tremendous opportunities for investigation on the part of the general practitioner.

Let us take the single illustration of the amount of exercise which cardiac cases should take. Obviously the hospitalized cardiac case is out of the question. If the hospitalized cardiac case recovers sufficiently to go home and resume ordinary life to a greater or less extent, he comes under the charge of the practitioner, and joins an already large group of cardiac cases with which any practitioner is always familiar. These cases will be under the observation of a general practitioner for a period of many years. They offer opportunities for carefully recorded data which, would be of inestimable value to the medical profession. There is, perhaps, a tendency among medical men to assume that the dictum of rest in a cardiac case has been somewhat overemphasized, but there are at the present time no sufficient data upon which to justify that assumption. The general practitioners could contribute tremendously important data upon that particular point.

I have, perhaps, given sufficient illustrations to indicate my general suggestions. I have not attempted to outline the definite shape and scope of the investigations which might be carried on by the general practitioner. Each practitioner will find readily available, ample material so that he may undertake the kind of investigation which his interest and his material indicate.

I realize fully, as I have said before, that general practitioners are busy men; that all too often every moment is devoted to urgent matters which cannot be postponed, but I have not attempted to make out of the general practitioner a laboratory worker, but have tried to indicate to him how he can utilize the already existing opportunities and how he can assist in the development of these facilities for his own advantage. I have tried to show that particularly in the study of early disease, and in the treatment of chronic disease, the general practitioner has a vantage position in which he has unexcelled opportunities. I have tried to outline some of the requisites which seem to me to be important in the utilization of his material for investigation. I would like to repeat my emphasis upon the keeping of records, the utilization of existing laboratory facilities, and lastly, the cultivation of a viewpoint which will tend toward investigation and which will progressively cease to countenance any derogatory estimate of the value of the general practitioner, not only to the community, but to the medical profession.

Finally, by his investigations, the medical practitioner, like the laboratory worker, will only very rarely indeed make important scientific discoveries, but both the practitioner and the laboratory worker will prodigiously benefit themselves by their investigations. The benefit is not solely selfish, certainly not in the case of the general practitioner, because the community will be the ultimate gainer.

\section{A CASE OF RECURRENT BILATERAL PNEUMOTHORAX.}

By John B. Hawes, 2ND, M.D., Boston.

IN a recent issue of this Journal, * Morrison reports a case of recurrent spontaneous pneumothorax. In view of the interest in such cases and the fact that they are frequently overlooked and wrongly diagnosed, I am reporting a similar case of my own. The striking points of this case are:

1. That the pneumothorax when on the left side caused attacks of pain closely resembling angina and neuritis in the left shoulder and arm and when on the right side pain which at one time was thought to be due to disease of the gall-bladder.

2. The rather robust good health of the patient during the intervals between attacks and the absence of any permanent clinical signs of pulmonary tuberculosis, although during and shortly after his attacks of pneumothorax such signs were apparently plainly evident.

The details of this case are as follows:

F. E. G., age 27, married. Family history excellent; two brothers, one sister, wife and one child alive and well. Habits very good.

Previous History.-In the past, he had always been well and strong, with the exception of the usual children's diseases. Aside from these, he had never had any serious illnesis. His maximum weight was 138 some years previous to my first examination. His weight at that time was 130

Present Illness.-In 1911, when feeling perfectly well, he came down with a sudden attack of shortness of breath, pain in the right side of his chest, especially in the right shoulder-blade. There was a slight cough

*Boston Medical and Surgicat Journal. Vol. 185, No. 22, Dec. 1, 1921, p. 659: "A Gase of Recurrent Spontaneous Pneumothorax," Hyman Morrison, M.D., Boston. 
which lasted two weeks, during which time he did not go to bed. There was no fever and his cough soon disappeared, leaving him feeling perfectly well. Since this first attack in 1911, at intervals of approximately every six months, with the exception of one two-year period when he was free from this trouble, he has had attacks similar to this one above described except that the pain has been on alternate sides. The striking feature of these attacks has been pain which comes on instantly without any warning, even when he is feeling perfectly well. This pain has apparently no relation to exercise or eating. It never comes on at night. When the attack is on the right side there is some soreness in the region of the gall-bladder. Never, however, has there been any jaundice or bile in the urine. He takes aspirin up to 40 grains daily to gain relief. He states very definitely that it is the pain which bothers him, and not the shortness of breath. When I first saw him, August 8, 1917, he had just been getting over such an attack on the right side, but on that day had had a mild attack of pain on the left. He has seen miany physicians in this city and has had thirteen $\mathrm{x}$-rays.

On physical examination, I could find nothing wrong with his lungs or elsewhere, except a temperature of 99.2 and a pulse of 96 , apparently of nervous origin.

$\mathrm{He}$ took his temperature and pulse four times a day at home, and reported to me again on August 13, 1917. Temperature and pulse during this period were absolutely normal, and again my examination was negative.

urine, blood and sputum were likewise perfectly normal.

The remarkable point in this case is the fact that when I first saw him he brought with him an x-ray plate, taken by Dr. Arial George of this city, about ten days before, which clearly showed practically a complete pneumothorax on the right side. This $x$-ray was taken on account of suspicious symptoms referred to the gall-bladder, and the pneumothorax was found purely by accident. I admit frankly that I found it difficult to believe the evidence, even though presented by the x-ray.

October 31st, 1917, nearly three months later, I saw this man again. He told me that he had been perfectly. well up to six days previous, when he had been taken with another severe attack of "neuritis," this time on the left side of his chest and in the left shoulderblade. There was no cough or sputum. It was not so severe but that aspirin could control it. After three days of this, there was a sudden, much more severe attack of pain associated with some shortness of breath, doubling him up to the left, along with coughing and sputum. His family physician in Brookline sent him to see Dr. E. W. Taylor of this city for an opinion concerning this so-called neuritis. Dr. Taylor found nothing to account for the pain, but did discover an irregular heart for which he. in turn, sent him to the Peter Bent Brigham Hospital. Here the heart was found to be normal, but x-ray showed a complete pneumothorax on the left side.

Physical examination at this time-October 31st-showed increased voice and breath sounds at the right apex, with a few fine crackles in the region of the spine of the scapula behind on the right. The lower one-half of the left chest was hyper-resonant, with nearly absent voice and breath sounds. The heart was slightly to the right. Examination of the sputum was negative.

Two weeks later I saw him again. Although his symptoms were subsiding, he still had 2 slight cough with raising in the morning, and found it difficult to sleep on his left side. There was evidently still some air in the left pleural cavity.

December 17,-a month later,-I saw him again, when he was feeling very well, with no symptoms of any kind. His lungs at that time appeared to be perfectly normal. He went to Saranac Lake, but remained only three weeks. An x-ray taken at the Trudeau Sanatorium, according to the report given me by the late Dr. Robert C. Paterson, showed "about as healthy a pair of lungs as it is possible to see. There are some adhesions between the right lower lobe and the diaphragm. These and a few apparently calcified tubercles are the only things that are at all noteworthy."

On October 19, 1918, when I next saw this patient, he told me that he had been accepted for the army, although he had been rejected for aviation on account of muscular eye trouble.

Four months later,-February; 6, 1919,-I again saw him. He reported that he saw only one day of service and likewise that he had had no more attacks of pain or pneumothorax. His complaint at this time was weakness and lack of energy. I could find nothing wrong with his lungs.

Six weeks later,-March 25, 1919,- he came to see me again, looking well, up to the maximum weight, but complaining of soreness in the center of his chest, increased on coughing. I could find nothing wrong with his lungs in any way.

December, 27, 1919,-nine months later,-I saw him for the last time. He had been perfectly well during this period, until the night previous to this visit when, out at dinner, he was taken with a very bad pain in the left chest, with shortness of breath, coming on suddenly out of a clear sky, without warning. An x-ray of his chest taken at this time by Dr. Arial W. George and Dr. Ralph D. Leonard, dated December 29th, 1919, is as follows: 
"We find a pneumothorax on the left side, due to partial collapse of the left upper lobe. There is no x-ray evidence of any active disease in either lung."

There was considerable shock, prostration, and great pain accompanying this last attack, apparently a very severe one. Physical examination showed the heart to be two inches to the right. The right lung appeared to be normal; the left chest was hyper-resonant all over, except in the base and axillary region, where there was dulness, with numerous rubs and dry râles. There was diminished and almost absent breathing elsewhere, especially over the back on the left, where there were practically no breath sounds to be heard.

Since this last examination of December, 1919, I have not seen or heard from this patient until December, 1921, when I received word from him in Florida, where he had estahlished himself in the cultivation of oranges. He. wrote as follows:

"My health has been very good for the past two years. I have had several attacks of my old trouble, but they have been very slight, and pass away in a few days. The attacks seem to come in periods of six months. They do not trouble me very much, except to cause pains in my chest and back, around my shoulder; also there is some shortness of breath for a little while. I feel sure that neither of my lungs has collapsed to any great extent. The pains I have are like pleurisy, and do not stay in any one place. I am living out-doors, practically the whole time, and outside of the few troubles mentioned above, my general health is fine. My weight remains about the same125 pounds-and I am able to do quite a lot of out-door work around my farm."

This is a striking and interesting case, demonstrating various important facts:

1. It demonstrates clearly what is to me an important and encouraging point, namely, the curability of tuberculosis. There have been a dozen times in the past ten years that this young man has had these attacks of pneumothorax when moisture in the way of râles, rubs, etc., have been present in his chest, but which have entirely cleared up, apparently, in two or three weeks' time.

2. It has shown, as mentioned before, that these attacks of pneumothorax, especially the mild ones, may closely simulate other non-pulmonary conditions, such as neuritis, gallbladder disease, angina, etc.

3. Finally, it has shown the need of the routine careful examination of the chest, even under conditions when the symptoms do not point directly toward heart or lung disease.

THe American Association of Anaesthetists and the Mid-Western Association of Anaesthetists will hold a foint meeting in St. Louis, May 23-24, at Hotel Jefferson, the first three days of the A.M.A.
PRESENT CONCEPTION OF COLON PYE. LITIS AS REGARDS TREATMENT.*

By E. Granville Crabtree, M.D., Boston.

IN this brief communication I plan to give what surveys of recent literature as well as my own experience, gleaned from cases seen during the past two years, indicated to be worth-while procedures in the handling of colon pyelitis. I shall not attempt to give any of the arguments on which this work is based.

\section{ACUTE PYELONEPHRITIS.}

A survey of the reports from a number of observers in many different clinies shows that, irrespective of the drugs used, the prognosis for cure of acute colon bacillus infections of the kidney is about equally good. All have made use of the same essentials of treatment; namely, rest in bed, light diet, forced fluids, and the treatment of pain and bladder distress by appropriate drugs. Some observers have done nothing further. Most observers prefer to alkalinize the urine with sodium bicarbonate or sodium citrate at the beginning of the infection, some preferring to use sodium citrate after a short course of hexamethylenamine. In still other instances the course of the disease has been studied in cases where the intake of fluid has been kept low to insure greater concentration of the formalin in the urinary passages. The majority seem to prefer hexamethylenamine given with copious intakes of fluid. Since the results are not vitally different under these various forms of treatment we are justified in considering acute colon pyelitis somewhat in the nature of a self-limited condition in which the aim of the physician in charge is to contribute to the comfort of the patient and to give those drugs which are best tolerated in that particular individual. It is undeniable that certain inflamed bladders will tolerate hexamethylenamine and that others are aggravated by it but will be made comfortable by either complete alkalinization of the urine or reducing acidity by the alkali drugs. Cystoscopic examination and bladder instrumentation are usually contraindicated during the acute stages of the disease.

\section{CHRONIC PYELITIS.}

Acute pyelonephritis, whether it marks the onset of the infection or is an exacerbation of a chronic condition, in its quiescent state becomes pyelitis. In this form it is capable of persisting for an indefinite period of time. I have endeavored to determine some facts as to what becomes of these cases. They fall into three classes.

1. Many infections disappear completely and patients remain cured after a few weeks * Read at a meeting of the Out-Patient Staff of the Massachusetts
General Hospital, January 25, 1922 . 